\title{
Stimulation of Cognitive Functions in University Students with Obsessive Compulsive Disorder Using Captain's Log Computerized Cognitive Training Program
}

Luz María Álvarez, Norma Yépez ", María Martina Jurado, José Benjamín Guerrero, Ileana Petra

Psychiatry and Mental Health Department, Faculty of Medicine, National Autonomous University of Mexico, Mexico City, Mexico

Email address:

lmalvarezp@yahoo.com (L. M. Álvarez),normayepez@yahoo.com.mx (N. Yépez), idamar007@gmail.com (M. M. Jurado), jbengl.com.mx@yahoo.mx (J. B. Guerrero), ileanapetra@yahoo.com (I. Petra)

${ }^{*}$ Corresponding author

To cite this article:

Luz María Álvarez, Norma Yépez, María Martina Jurado, José Benjamín Guerrero, Ileana Petra. Stimulation of Cognitive Functions in University Students with Obsessive Compulsive Disorder Using Captain's Log Computerized Cognitive Training Program. American Journal of Applied Psychology. Vol. 7, No. 1, 2018, pp. 1-10. doi: 10.11648/j.ajap.20180701.11

Received: December 3, 2017; Accepted: December 14, 2017; Published: January 12, 2018

\begin{abstract}
The Obsessive Compulsive Disorder (OCD) has significant implications for quality of life of a person. This study proposes the use of a cognitive stimulation program (Captain's Log Cognitive Training) to improve the cognitive deficits produced by this disorder. Ten university students with OCD were randomly selected; 4 of them (control group) received psychiatric and pharmacological treatment, and six students (experimental group) received training using a computer program that stimulated the cognitive deficits besides the psychiatric and pharmacological treatment. A pre and posttest neuropsychologic evaluations were applied using the Wechsler Adult Intelligence Scale (WAIS-III) and an abbreviated version of the Barcelona Test. Training was carried out twice a week until each subject covered 30 sessions. Significant differences were found $(\mathrm{p}<0.05)$ in functions associated with Planning skills, anticipation and organization, verbal fluency, visuoconstructive praxis, working memory and processing speed. Cognitive training helped to improve the intellectual performance of the students who participated in the treatment, reflected in higher flexibility to solve practical problems.
\end{abstract}

Keywords: Obsessive Compulsive Disorder, Students, Cognitive Functions

\section{Introduction}

The Obsessive Compulsive Disorder (OCD) is characterized by the presence of obsessions (recurrent, persistent, intrusive and unwanted thoughts, impulses or images) and compulsions (repetitive behaviors in response to an obsession) that may cause severe discomfort or dysfunction or in general activity. [1]

Patients with OCD respond favorably to pharmacological therapy and cognitive behavioral therapy; however, remission is incomplete in all the patients, since between 20 and $60 \%$ of the cases remain with symptoms that can't disappear despite the treatment. [2]

OCD affects between 2 and 3\% of world population, while in Mexico, according to the Psychiatric Epidemiological Survey [3], total prevalence was about $2.6 \%$, with an average age of onset of 19 years. According to Caraveo [4], in
Mexico City prevalence was approximately $1.4 \%$ and the average age of onset between men and women was 22 years. In the Psychiatry and Mental Health Department, it presents as principal diagnosis in $1.8 \%$ of the patients who attend for service.

OCD is one of the disorders with more comorbidities within mental illnesses. It is associated with other disorders such as major depressive disorder, bipolar disorder, social anxiety disorder, specific phobias and generalized anxiety disorder. [1]

As Carretero \& Palacios [5] mentioned, the disorder itself implies a series of problems to the patient, who will face diverse academic demands, difficulties on learning development, and the acquisition of skills when going to college that may cause failure or success that, added to their study rhythm, schedules intensities, teachers' demands, group pressures, peer competitiveness, changes in diet 
schedules and sleep-wake cycle, can disturb their already vulnerable health condition due to the disorder they present.

In order to treat OCD symptoms, besides pharmacological treatment, several therapies have been used to obtain higher functionality in these cases. Exposure and Response Prevention [6] has been considered as the treatment of choice for this disorder. Other therapies used are Individual Cognitive Psychotherapy [7], Acceptance and Commitment Therapy [8], Evidence-based treatment [9], Neuropsychological Rehabilitation [10] or cognitive stimulation programs to enhance cognitive decline. [11]

There is evidence about a cognitive deficit in people with OCD; mainly it has been observed a change in executive functions and memory, which emerge as an intermediate variable between neurobiological abnormalities and clinical manifestations of the illness.

Nowadays the exact etiology is unknown, even though several theories consider as the possible origin the impairment in frontal lobes, basal ganglia and mainly changes in frontal-subcortical circuits. $[12,13]$

In the same way, trials carried out in patients with OCD reveal that the neuropsychological variations presented in these patients are attention, intellectual function, visuospatial and verbal memory, ability to evoke words and executive functions. [14]

Flores, J. and Ostrosky, F. [15] suggest that there is no single executive function; however there are different processes that converge in one general concept about Executive Functions. Among all the described ones, these stand out: planning, behavioral control, mental flexibility, working memory, and fluency.

OCD could be related to a deficit in processing information, according to the clinical neuropsychology's point of view. The most affected cognitive functions are visuospatial and visuoconstructive abilities, nonverbal memory and executive functions. Hence, these patients could have difficulties to understand the global stimuli, focusing on details. [14, 16]

The frontal lobes take part integrating the information of the outside environment, inside and emotional states. Thanks to them, the functions and abilities that differentiate humans from the rest of the living beings can be carried out. Motivation, initiative, attention, memory, language, motor behavior, planning and organizing complex situations or the ability to understand other peoples' emotional states are some of the quotidian aspects in which the role of the lobes is fundamental. [13, 17]

According to Martínez et al., [14], the reason some authors attribute to the non-verbal memory deficit in patients with OCD is due to the significant difficulty they present in mnesic encoding when assignments are defined with less clarity. Instead, when assignments require a memory under well-structured circumstances, patients with OCD show a similar performance as the control group. Therefore, the memory deficits presented in these patients wouldn't be caused by a memory failure, but in the unskillful use of strategies.
Tests that have researched for executive functions using Functional Magnetic Resonance Imaging have also identified differences in frontostriatal circuits in patients with OCD, particularly in prefrontal cortex and caudate nucleus, as well as in the response inhibition as neurocognitive substrate. [18, 19]

Another important trial to mention is the one carried out by Sharma [20], who used the Wisconsin Card Sorting Task (WCST) and the Conners' Continuous Performance Test (CPT). The results on both tests point out that patients with OCD have a specific pattern of cognitive deficits related to spatial working memory, changing system, abstract reasoning, planning skills, concentration and attentional tasks.

Reference [21] point out the importance of the involvement of a therapeutic interdisciplinary team to handle mentally ill patients, helping them recover their functionality and boost their cognitive performance, facilitating their reintegration to society and guiding them on rehabilitation to acquire practical habits in quotidian life that will help them in their social interaction and to stay cognitively active. However, concerning cognitive rehabilitation of a patient with OCD, there is limited evidence about this method. The literature describes some studies like the one that Williams, Evans, and Fleminger [22] carried out in the year 2003, where they considered that cognitive behavioral therapy combined with cognitive rehabilitation resulted considerably useful in a patient with a cranioencephalic trauma who had developed OCD.

\section{Rehabilitation using computer programs}

The stimulation of cognitive functions using computer programs appears in the 1980s decade, mainly in the educational field, causing interest in the results and its use, even in patients with brain injury.

These practices constitute a hierarchical approach, where subjects are trained in an orderly sequence of problems from minor to higher complexity to rehabilitate main cognitive functions.

According to a conceptual point of view, most of the programs that have software support are based on a classical conception of rehabilitation, which considers that stimulation and repetition of exercises help restore the declined function.

Reference [23] carried out a case study research where they demonstrated that Captain's Log Cognitive Training software was able to produce changes in brainwave patterns tested on the electroencephalogram (EEG)/neurofeedback equipment. These changes were measured in a 13-year-old patient diagnosed with Attention Deficit Hyperactivity Disorder (ADHD), in a pre-test/ post-test design. The patient received 35 treatment sessions presenting significant improvement of the symptoms; changes remained after seven months after the experimental procedure concluded [24, 25].

On the other hand, brain images of adolescents who have played Tetris during three months showed an increase in thickness of the cerebral cortex [26], demonstrating that computer games can make changes in the cerebral cortex and therefore, in behavior. 
Reference [27] showed in an experimental way that Alcor Program was efficient as a treatment for depression and in the reduction of the cognitive deterioration in patients with Major Depressive Disorder; they also demonstrated that the program significantly increased the patients' intellectual quotient.

While talking about cognitive rehabilitation, the use of information technology represents a tool that cannot be ignored. Therefore, the appropriate clinical use of the software requires to be considered as another component of the treatment and not as an independent alternative that by itself substitutes the active participation of the therapist who supervises and controls its correct use.

As we mentioned before, there is less evidence about the rehabilitation of cognitive functions in patients with OCD. That is why this investigation mainly focused on the contributions of Cognitive Stimulation, based on the brain's plasticity (neuroplasticity), that is, the ability of the brain to substitute damaged or impaired connections for near intact connections that can decrease the effects produced by different dysfunctions or neurological damages.

\section{Objective}

To evaluate the impact of a computerized cognitive training program to determine if there is a change in cognitive function in patients who received the therapy mentioned above.

\section{Materials and Methods}

In this study participated university students who attended a mental health clinic at the National Autonomous University of Mexico (UNAM), diagnosed with OCD according to the Diagnostic and Statistical Manual of Mental Disorders, 4th Edition (DSM IV) [28]. The diagnosis was confirmed with the Spanish digital version of the M. I. N. I (MiniInternational Neuropsychiatric Interview) [29], based on the DSM-IV and International Statistical Classification of Diseases and Related Health Problems (ICD-10).

The criterion used to define the sample was of 20 individuals divided into two groups: experimental group $(\mathrm{N}=10)$ and control group $(\mathrm{N}=10)$. All of the participants received pharmacological treatment using Selective serotonin reuptake inhibitors, and only the experimental group received cognitive stimulation sessions. Written informed consent was obtained from all participants.

During the investigation process 20 subjects were recruited; nevertheless, due to the patients' inconsistent attendance, only four subjects from control group stayed in their medical monitoring, and six subjects from experimental group finished the 30 training sessions that were established as part of the investigation's criterion. Before starting the treatment, patients from both groups were assessed using the Wechsler Adult Intelligence Scale (WAIS-III, standardized version for Mexican population, 2009), the abbreviated version of the Barcelona Test (Adapted for application in Mexico, 1999), and the Mini-International Neuropsychiatric Interview (M. I. N. I. version 5.0, 2000).

Regarding the ceiling effect that some of the tests that assess cognitive functions in test re-test phases may present, the reason why the WAIS-III was used was that some trials that were carried out with past Weschler scales [30] showed that the effects of the practice of the Executive subtests decrease to a minimum after a year or two between test-retest applications; for the verbal subtests, interval was shorter. [31]

Captain's Log Cognitive Trainer was used as a designed program for cognitive training. [32] There were two sessions a week of 45 minutes each, starting with the memory unit and afterward with logical reasoning unit. Both groups were assessed at the end with the same tests from the beginning, to estimate the intervention's impact.

\section{Results}

The statistics from the data were analyzed using the Wilcoxon Signed Rank Test (version $6<\mathrm{N}<25$ ), which is a non-parametric statistical test to compare two related measurements and determine whether the difference between them are due to chance or not and to determine if the difference was statistically significant. Results demonstrated that changes were due to the experimental variable; therefore, the hypothesis was confirmed. Runs tests analysis showed that the data sample is random with significant values $(\mathrm{p}>0.05)$.

A contrast analysis was carried out in the entire sample $(\mathrm{N}=10)$ of the test-retest punctuations, finding statistically significant differences in the next subtests: Picture completion $\quad(p=.016), \quad$ Similarities $\quad(p=.047)$, Picture Arrangement $(p=.036)$, (Figure 1). There were also found statistically significant differences in Verbal IQ $(p=.017)$, Performance IQ ( $\mathrm{p}=.012)$, Full-Scale IQ $(\mathrm{p}=.008)$ (Figure 2). As well as in Verbal Comprehension Index $(p=.025)$, Perceptual Organization Index $(p=.017)$ and Working Memory Index $(p=.032)$ (Figure 3).

When analyzing the initial and final assessment of the experimental group, statistically significant differences were found in the next subtests: Picture Arrangement $(p=.026)$, Object Assembly $((\mathrm{p}=.042)$ (Figure 4). Also, there were found statistically significant differences in Verbal IQ $(\mathrm{p}=.042)$, Performance IQ $(\mathrm{p}=.027)$, Full-Scale IQ $(\mathrm{p}=.028)$ (Figure 5). As well as in Perceptual Organization Index $(\mathrm{p}=.043)$, Working Memory Index $(\mathrm{p}=.027)$ and Processing Speed Index $(\mathrm{p}=.046)$ (Figure 6). 


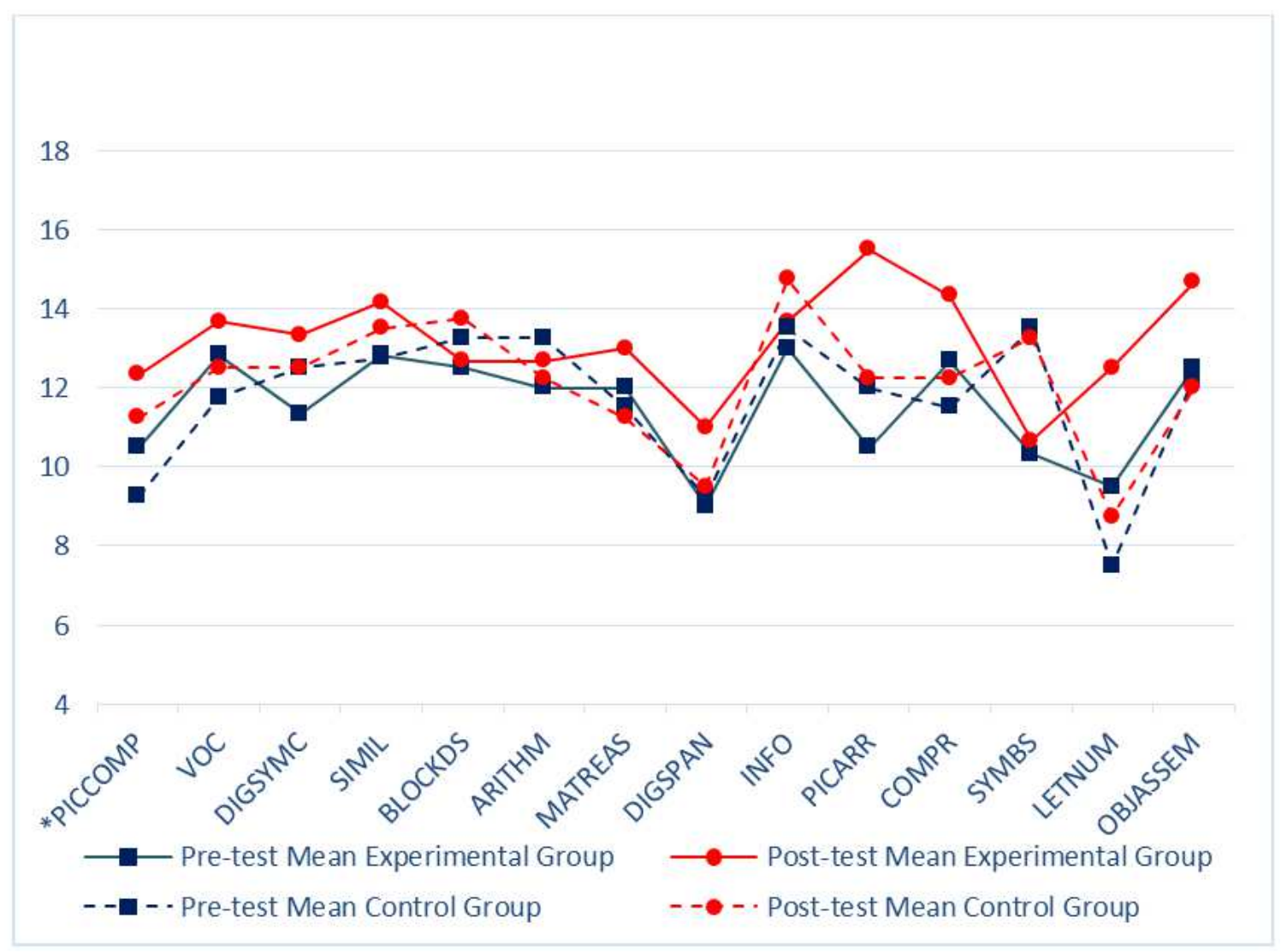

Figure 1. WAIS-III Subtests. Comparative pre and post-test groups.

*PICCOMP: Picture completion VOC: Vocabulary DIGSYMC: Digit symbol-coding SIMIL:Similarities BLOCKDS: Block design ARITHM: Arithmetic MATREAS: Matrix reasoning DIGSPAN: Digit span INFO: Information PICARR: Picture arrangement COMPR: Comprehension SYMBS: Symbol search LETNUM: Letter-number sequence OBJASSEM: Object assembly.

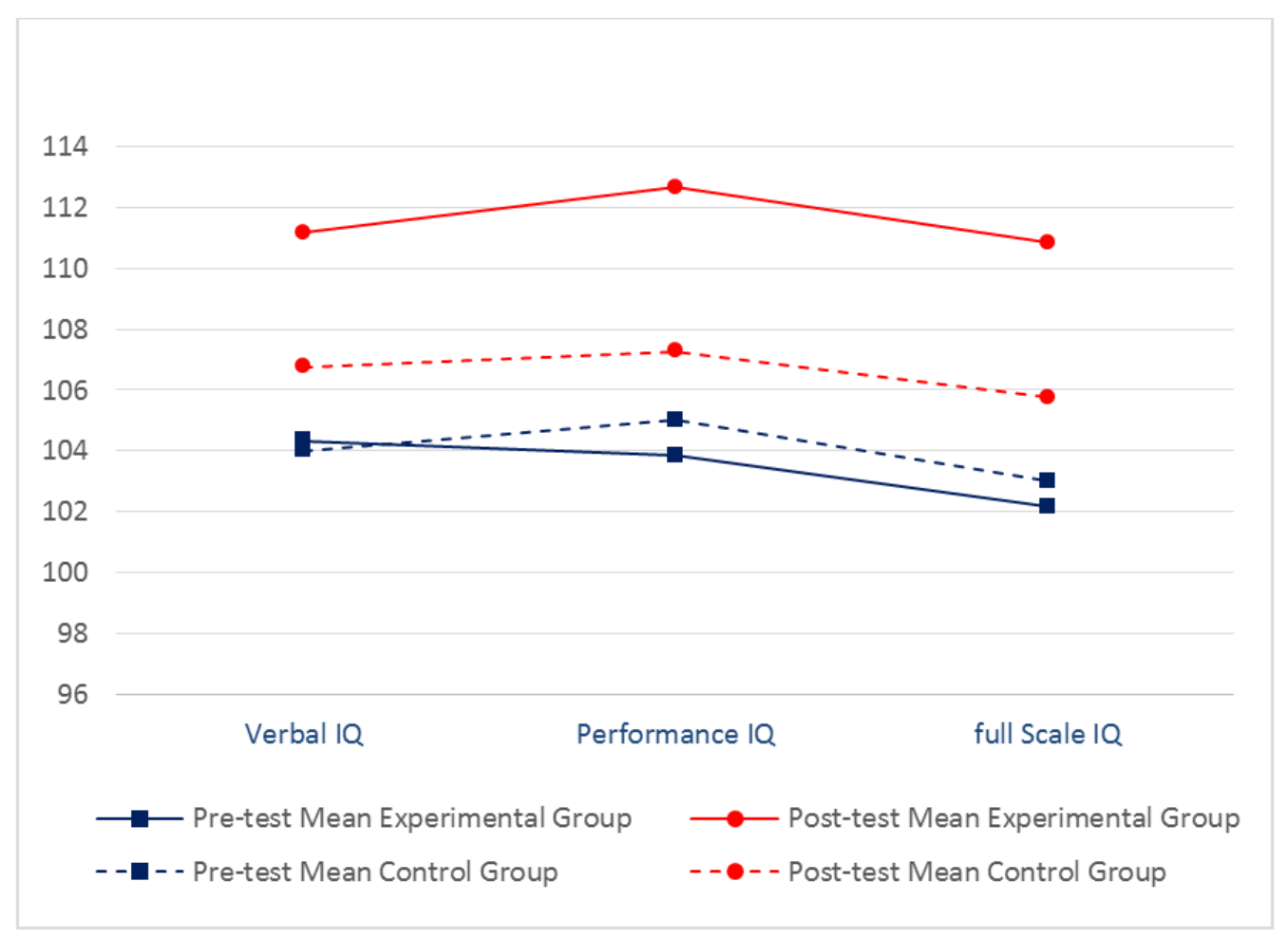

Figure 2. WAIS-III Intelligence Quotient. Comparative pre and post-test groups. 


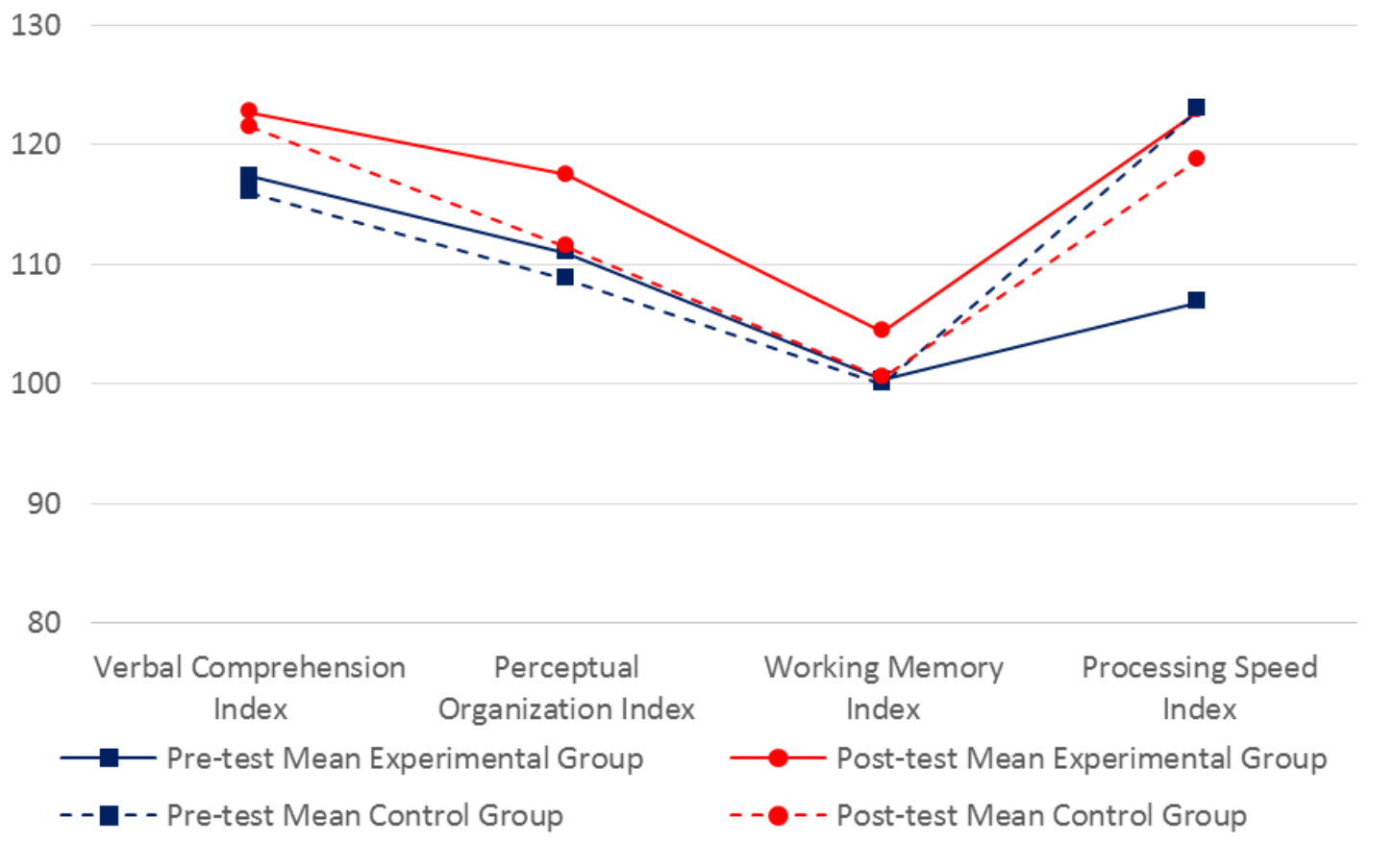

Figure 3. WAIS-III Indexes Comparative pre and post-test groups.

18

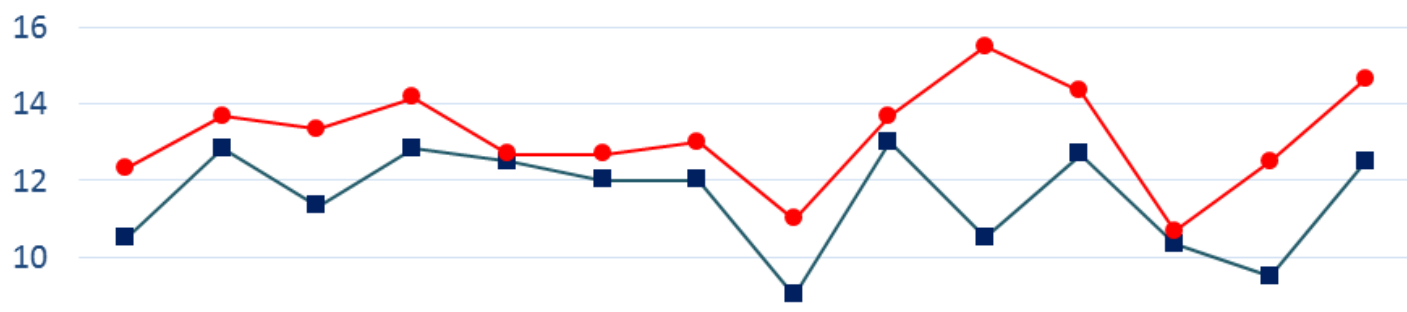

8

6

4

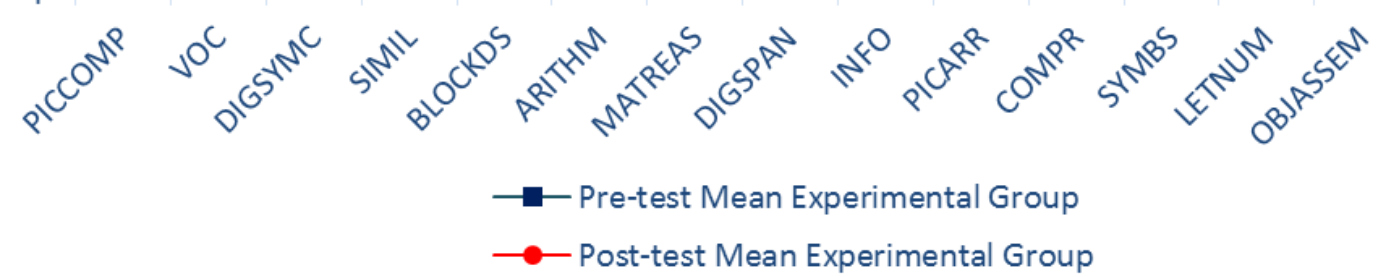

Figure 4. Experimental group subtest WAIS-III Pre and Post test. 
Luz María Álvarez et al.: Stimulation of Cognitive Functions in University Students with Obsessive Compulsive Disorder Using Captain's Log Computerized Cognitive Training Program

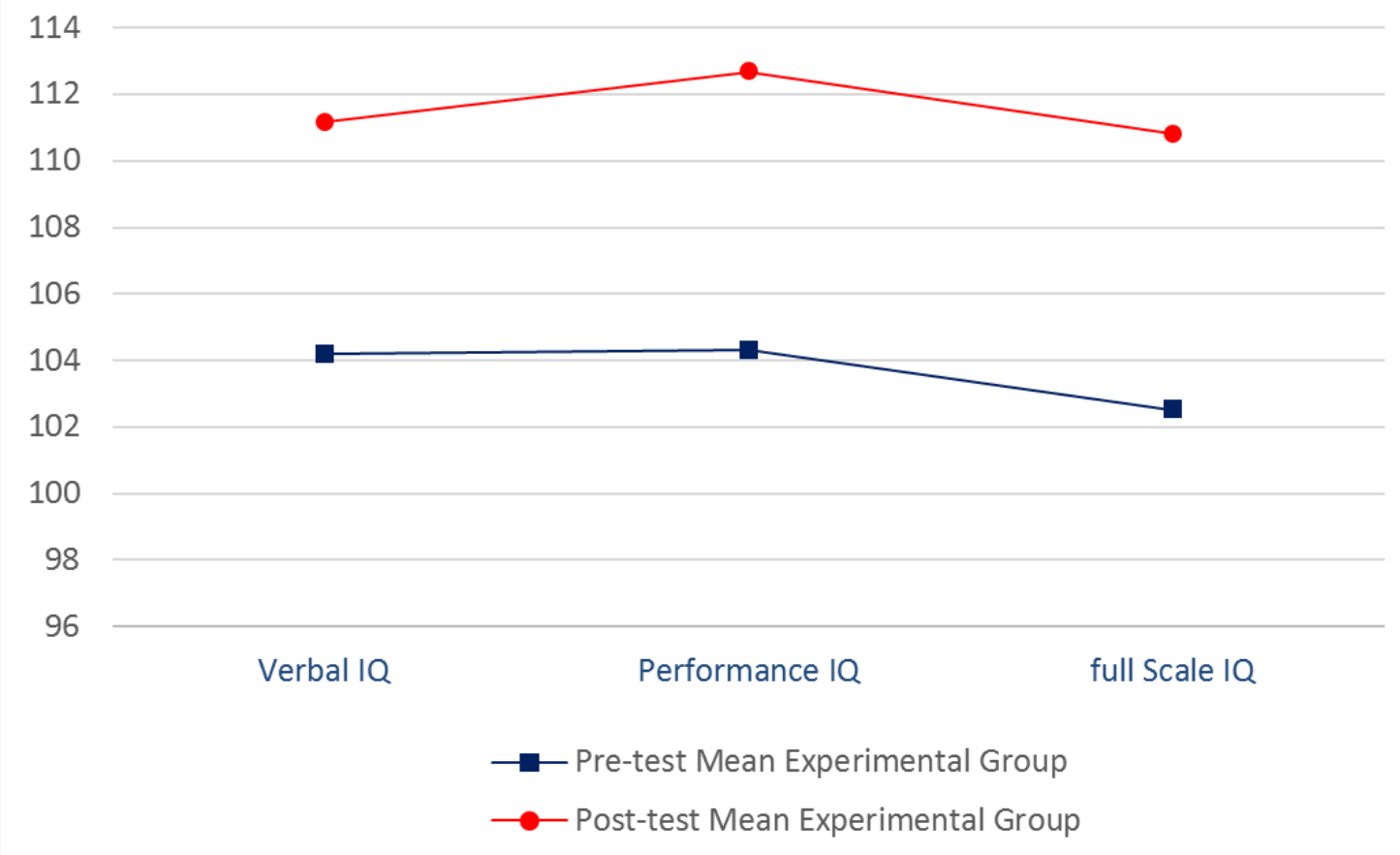

Figure 5. Differences in experimental group Intelligence Quotient Pre and Post-test.

130

120

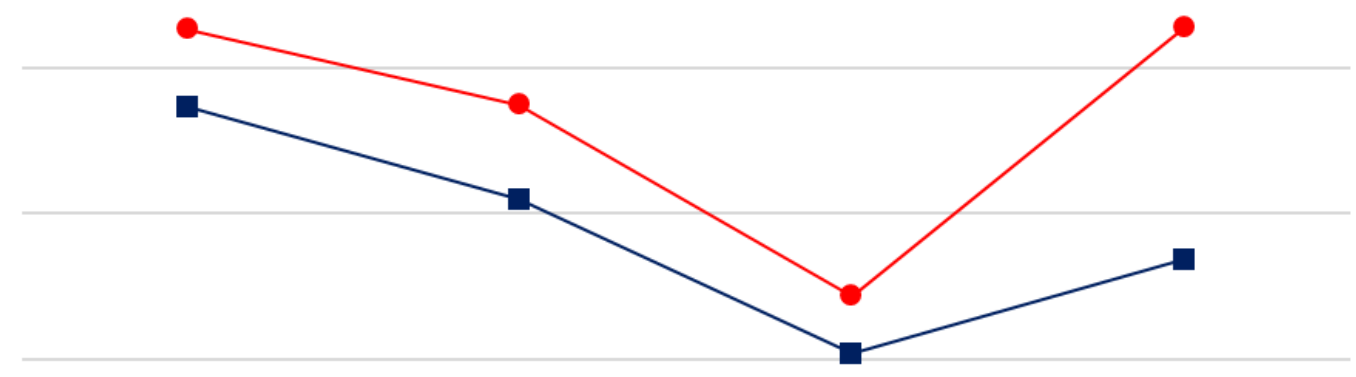

90

80

\begin{tabular}{|c|c|c|c|}
\hline $\begin{array}{c}\text { Verbal } \\
\text { Comprehension Index }\end{array}$ & $\begin{array}{c}\text { Perceptual } \\
\text { Organization Index }\end{array}$ & $\begin{array}{c}\text { Working Memory } \\
\text { Index }\end{array}$ & $\begin{array}{c}\text { Processing Speed } \\
\text { Index }\end{array}$ \\
\hline
\end{tabular}

$\longrightarrow$ Pre-test Mean Experimental Group

- Post-test Mean Experimental Group

Figure 6. Comparative indexes WAIS-III of experimental group. 


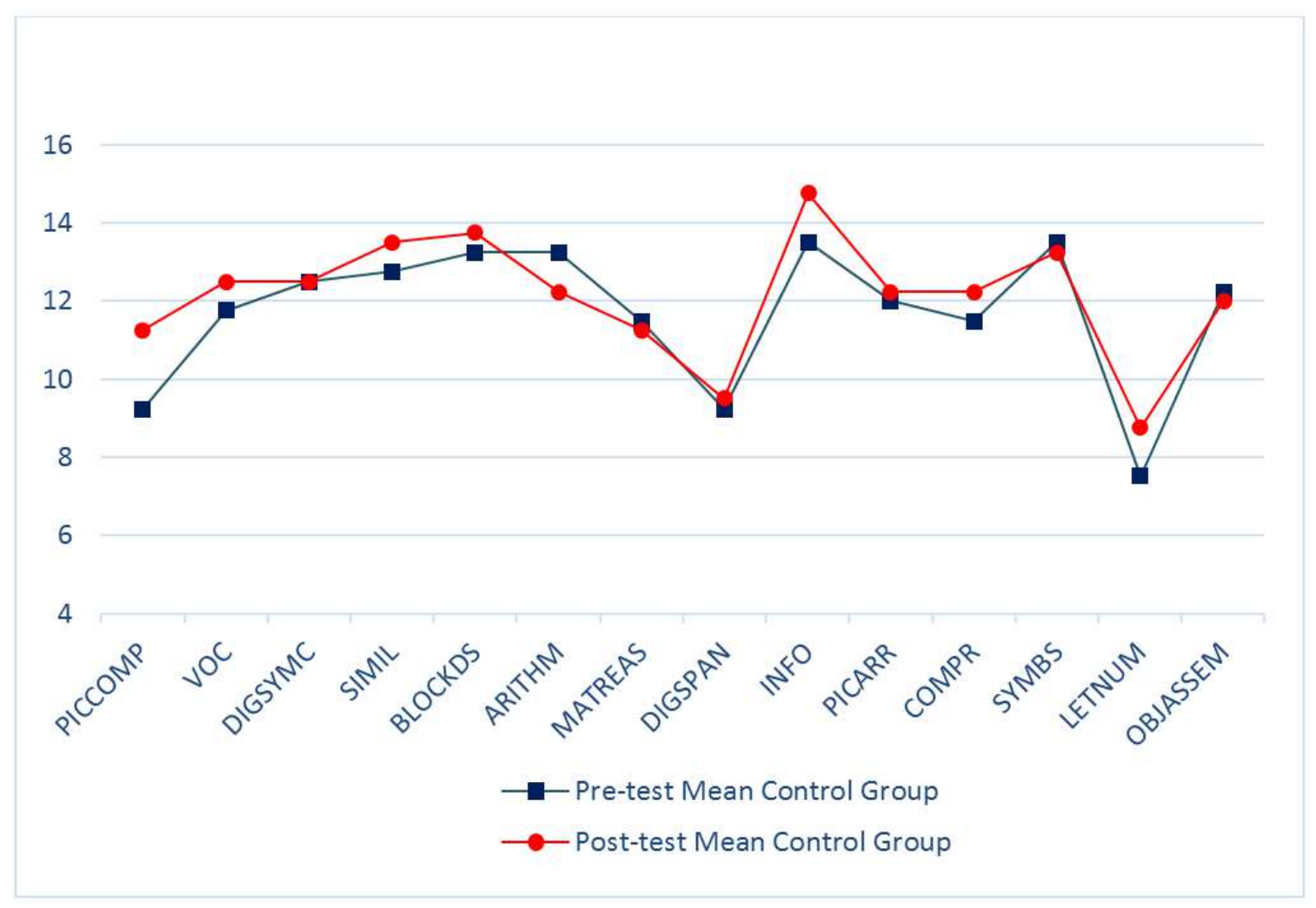

Figure 7. Control group WAIS-III Subtest comparative Pre and Post-test.

In the contrast analysis from the control group, there were no statistically significant differences as we can observe in Figure 7, meaning that subjects stayed without changes between initial and final punctuations.

In the statistical analysis carried out in the Barcelona Test, there were no significant differences between both groups.

\section{Discussion}

As it was mentioned before, OCD has important repercussions in cognitive and emotional functioning that affect every aspect of the patient's life.

Focusing on the study population, all of the subjects possess adequate intellectual capacities that could favor an appropriate functioning in their academic tasks as well as in their life; however, the disorder could limit in a significant way their adaptation, academic performance, hence, their quality of life.

Therefore the importance of demonstrating that in the intervention group there were changes in diverse cognitive functions, mainly in those that let them endure their academic tasks and general adaptation.

In the experimental group, there were found significant changes in Picture arrangement subtest, which is associated with functions such as perceptual organization, interpretation of social situations, non-verbal reasoning, attention to detail skills, visual sequencing, and logical reasoning. These changes are meaningful because these functions were specifically stimulated with Captain's Log Cognitive Training system, which evidences the effectiveness of such training.

Another significant change was in Object Assembly subtest, which is related to functions such as perceptual organization, visuomotor coordination, synthesis of specific parts from a whole, spatial relationships and concentration. These results are impressive because they detect a change in patients who received cognitive training in cognitive functions; that is, on problem-solving skills, since OCD patients characteristically tend to create fixed pattern behaviors and perseverance, due to their inability to change the pattern when an alternative response is required. [33] These show higher cognitive flexibility in patients who received training.

Regarding Verbal IQ, significant differences were found in control group, indicating changes in the subjects' ability to respond to stimuli of linguistic aptitude, verbal concept formation, verbal richness, and the semantics of the environment where the assessed subjects develop. [31] Some authors such as Mataix et al. [16] in 2006 and Martínez [14] in 2008, pointed out a deficit in information processing related to frontal areas, and others like Ardila and Ostrosky [34] in 2012, reported that verbal fluency tests are sensitive to the dysfunctions of these areas in patients diagnosed with OCD.

Performance IQ demonstrated a significant change since training with Captain's Log program was carried out, enhancing logical reasoning using visuospatial stimuli and solution of new problems. This reinforces the learning ability of the patients, which is a fundamental aspect of the academic tasks they perform. 
The impact of cognitive training was also reflected in FullScale IQ, which favored the ability to understand and assimilate information to use it later in the resolution of practical problems. This condition is crucial because as it is mentioned in the literature, the repetitive thoughts in this disorder tend to complicate decision making and the practical application of their abilities in new situations.

Perceptual Organization Index also reflected a significant change related to analysis and synthesis ability, visual-motor integration, concept formation through visual stimuli, as well as visual organization and perception. Okasha et al. [35] carried out a trial with patients with OCD using the Wisconsin test and the block subtest of WAIS-II. There they detected that these patients suffer an excessive interference in information processing, in this case, visuospatial and the impossibility to overlook irrelevant signals; therefore, the cognitive training implemented in this study could influence such deficit.

The statistical analysis reported significant changes in Working Memory Index in the experimental group; this index measures the ability to temporarily hold a certain amount of information in memory as well as the ability to stay focused and reach mental control. Velilla L. M et al., [11\} carried out an examination aimed at patients with amnestic mild cognitive impairment instead of patients with OCD, detecting statistically significant differences and clinically relevant findings on working memory components, especially on visual loop and central executive. Consequently, the program of cognitive stimulation enhanced these areas.

There were also found significant differences in Processing Speed Index related to the ability to explore, order and discriminate visual information directly and efficiently. It is also associated with visual short-term memory, attention skills, and visuomotor coordination.

It is important to mention that a central aspect of OCD is the fact of spending too much time performing a task, as a result of difficulties with decision making. That is why the findings regarding the increase in processing speed within training group are truly significant because that could favorably influence over an efficient perform of their quotidian tasks and improve their quality of life. Regarding this, Martínez and Piqueras [14] in 2008, mention that OCD patients present a deficit to change focal point towards stimuli, problems on response inhibition and in the ability to create planning strategies.

From the point of view of Cognitive Stimulation, the concept of brain plasticity is relevant because under appropriate and constant stimulations, and carrying out an organized practice and repetition as in Captain's Log training system, the brain can favorably modify its structure and functioning, indicating a possibility to optimize the performance and cognitive abilities. That is, it can learn under specific circumstances, promoting the acquisition of new skills. These aspects were extensively studied by Jones et al., in 2006 [36], and by Mercado, in 2008 [37].

Cognitive plasticity implies a contrast between the individual's current average level of performance under normative conditions and one's latent potential [38]. This modification has been uniquely related to the first months of life, however, nowadays plasticity is considered to be a phenomenon that involves the complete life cycle, and it is part of the basis of the adaptation to new environmental conditions [39]. Therefore, it is necessary to encourage the use of cognitive stimulation in basic education and high school as a way of support for the cognitive requirements that academic formation demands.

\section{Conclusions}

OCD has been considered one of the psychiatric disorders with more difficulty regarding its treatment and recovery of cognitive functions; however, with the findings from this trial, it can be stated that with the use of cognitive stimulation programs, this condition can favorably change. Pharmacological treatment combined with cognitive stimulation reinforces these changes.

It is recommended to reproduce this trial in younger subjects without psychiatric diagnoses and with dysfunctions associated to attention, concentration, and memory, to confirm the possible benefits that programs like the one used in this case may provide.

It should be noted that there were no changes in the punctuations of the first and second assessment in the Barcelona test in both groups, which may indicate that this test was not sensitive to detect differences on cognitive functioning of these subjects.

Also, it is important to mention that the cognitive function of the control group (which only received pharmacological treatment), stayed the same.

It is necessary to meticulously identify in the diagnostic phase the cognitive abilities affected in this disorder, to design programs that specifically stimulate those declined functions.

So, the Captain's Log Cognitive Training program is a reliable tool for the stimulation of affected functions in OCD, a situation that has already been approached in literature as a valid instrument that can be used with other populations that could benefit with this training.

It is important to have in mind the complexity of OCD, due to the comorbidity it presents and that it may often associate to Major Depressive Disorder, Social Anxiety Disorder, specific phobias, etc., which increases the difficulty of treatment.

\section{Limitations}

In future trials, it is recommended to have a larger sample size of subjects diagnosed with OCD, due to the high dropout incidence of these patients, which goes between 25 and $35 \%$, according to literature [43]. In this trial, the dropout index was about $50 \%$, which may be explained as a result of high anxiety, self-demanding, poor stress tolerance, fear of failing, and permanent doubt of execution, which seemed more emphasized in them. 
Although the WAIS-III Test was sensitive to the detection of cognitive changes produced by the intervention, Barcelona test was not optimal on the identification of these changes; this test is conformed of extensive areas of study that did not allow a comparison point.

The cut off points presented a variability that probably makes it even harder to compare with the results of the intelligence test used in this trial.

It would be convenient to use other assessments that could be able to detect the affected functions in this disorder efficiently.

The results of this trial only allow inferring about the obtained changes in this population, since there are no previous investigations with cognitive stimulation in people with OCD that could be compared with these findings.

\section{Acknowledgements}

This study was not funded by any grants. We want to express gratitude to the following individuals for their contributions:

Silvia Ortíz León, Master of Medical Sciences.

Gerardo Luna Guevara, Master of Engineering.

Silvia Aracely Tafoya Ramos, Doctor in Psychology.

Claudia Erika Ramírez Ávila, Psychologist.

Mariana Edith Rodríguez Lugo, Psychologist

\section{Conflict of Interest}

All the authors do not have any possible conflicts of interest.

\section{References}

[1] American Psychiatric Association. Diagnostic and statistical manual of mental disorders (5th ed.), American Psychiatric Association, Arlington VA, 2013.

[2] Mataix-Cols, D., Van den Heuvel, A., "Common and Distinct Neural Correlates of Obsessive-Compulsive and Related Disorders". Psychiatr Clin N Am, 29, 391-410, June 2006.

[3] Villatoro, V., Jorge, A., Medina-Mora, M., Hernández, M., Fleiz, C., Amador, N. Bermúdez, P., "La encuesta de Estudiantes del Nivel Medio y Medio Superior de la Ciudad del México: noviembre 2003. Prevalencias y evolución del consumo de drogas". Salud Mental, 28, 38-51, Febrero, 2005. [En línea]. Disponible en: http://www.redalyc.org/articulo.oa?id=58212805. [Fecha de consulta: 16 Junio 2017].

[4] Caraveo-Anduaga, J. \& Colmenares, E., "The Epidemiology of Obsessive-Compulsive Disorder in Mexico City". Salud Mental, 27 (2), 1-6, Abril 2004.

[5] Carretero, M., \& Palacios, J. Psicología Evolutiva: Adolescencia, madurez y senectud. Alianza, Madrid, España, 1995.

[6] Vallejo M. A., "Tratamientos psicológicos eficaces para el trastorno obsesivo compulsivo". Psicothema. Vol. 13, n 3 , pp. 419-427, Marzo, 2001.
[7] García F, Fernández, H, Behobi, W., "Psicoterapia cognitiva individual del TOC". Salud Mental 36, Julio-Agosto 2013.

[8] León-Quismondo L., Lahera, G., López-Ríos, F., "Terapia de aceptación y compromiso en el tratamiento del trastorno obsesivo-compulsivo". Rev. Asociación. Española de. Neuropsiquiatría. vol. 34 no. 124 Madrid, Junio 2014.

[9] Orly de Labra, A., Díaz, C. "Tratamientos basados en la evidencia para el Trastorno Obsesivo Compulsivo". Boletin Psicoevidencias, $\mathrm{n}^{\circ}$ 44, Abril 2016.

[10] Salas, Ch., "Rehabilitación Neuropsicológica en Chile: una disciplina latente". Revista. Chilena Neuropsicología. 9 (E1): $1-3,2014$.

[11] Velilla L. M, Soto E, Pineda, D., "Efectos de un programa de estimulación cognitiva en la memoria operativa de pacientes con deterioro cognitivo leve amnésico". Rev. chil. neuropsicol., 5 (3), 185-198, Diciembre 2010.

[12] Perpiña, A., Lázaro, L., Canalda, G., Boget, T., “Aspectos neuropsicológicos del trastorno obsesivo compulsivo". Revista de Neurología, 35 (10), 959-963. Noviembre 2002.

[13] Miller, B. \& Cummings, J., The human frontal lobes: functions and disorders. 2a Ed. Guilford Press, New York, 2007.

[14] Martínez, A., Piqueras, J., “Actualización neuropsicológica del trastorno obsesivo compulsivo". Revista. Neurología., 46 (10). 618-625, Mayo, 2008.

[15] Flores, J., Ostrosky, F., "Neuropsicología de Lóbulos Frontales, Funciones Ejecutivas y Conducta Humana". Revista Neuropsicología, Neuropsiquiatría y Neurociencias, 8 (1), 4758, Abril 2008

[16] Mataix-Cols, D., Junqué, C. Neuropsicología del trastorno obsesivo compulsivo. In Vallejo J, Berrios G, eds. Estados Obsesivos, 3ed, Elsevier-Masson, Barcelona, 2006, 75-90.

[17] Jódar-Vicente, M., "Funciones cognitivas del lóbulo frontal". Revista. Neurología. 39, 178-182, Julio 2004.

[18] Chamberlain, S., Blackwell, A., Fineberg, N., Robbins, T., Sahakian B., "The Neuropsychology of obsessive compulsive disorder: the importance of failures in cognitive and behavioral inhibition as candidate endophenotypic markers". Neurosci Biobehav Rev; 29: 399-419, May, 2005.

[19] Pena J, Ruipérez, M., Barros, A., "Neurobiología del trastorno obsesivo-compulsivo: aportaciones desde la resonancia magnética funcional (II)". Revista Neurología, 50: 541-50, Abril 2010.

[20] Sharma, S., Kumar, V., Trivedi, Dalal, P., Kumar, P., Sudarshan, S., Choudhary, S., "Neuropsychological Correlates for Obsessive Slowness. Delhi". Psychiatry Journal, Vol. 15 No. 1, April 2012.

[21] Quijano, M., Aponte, M. y Salazar, C., "Cambios Cognoscitivos en la enfermedad Mental de pacientes que asisten al programa de Hospital Día del Hospital Psiquiátrico Universitarios del Valle". Rev. Diversitas perspectivas en Psicología. 4 (1), 113-121, Diciembre 2008.

[22] Williams, W., Evans, J. \& Fleminger, S., "Neurorehabilitation and Cognitive- behavior Therapy of anxiety disorders after brain injury: An Overview and case illustration of obsessivecompulsive disorder". Neuropsychological Rehabilitation. 13 (1-2), 65-87, Jan-Mar, 2003. 
[23] Kotwal, D., Burns W. \& Montgomery, D., "Computer-assisted cognitive training for ADHD: A case study". Behavior Modification, I20 (1), 85-96, January 1996.

[24] Burda, P., Stakey, T., Domínguez, F. \& Vera V., "Computer administered treatment of psychiatric inpatients". Computers in Human Behavior, 10 (3), 359-368, 1994.

[25] Bell, M., Bryson, G. \& Wexler, B., "Cognitive Remediation of Working Memory Deficits: Durability of Training Effects in Severely Impaired and Less Severely Impaired Schizophrenia". Acta Psychiatrica Scandinavica. 108 (2): 101-109 (9), August 2003.

[26] Haier, R. J, Karama, S., Leyba \& L., Jung, R., "MRI assessment of cortical thickness and functional activity changes in adolescent girls following three months of practice on a visual-spatial task". BMC Research Notes 2: 174, September 2009.

[27] Alvarez, L., Cortés, J., Ortiz, S., Estrella, J., Sánchez, J., "Computer program in the treatment for major depression and cognitive impairment in university students". Computers in Human Behavior 24, 816-826, May 2008.

[28] American Psychiatric Association, Manual de Diagnóstico y Estadístico de los Trastornos Mentales. Texto revisado. Editorial Masson, Barcelona, 2005.

[29] Heinze, G. \& Cortés J., "Software para la aplicación de la versión española de The Mini-International Neuropsychiatric Interview (MINI)". Instituto Nacional de Psiquiatría Ramón de la Fuente Muñiz, Enero 2000.

[30] Matarazzo, J., Carmody, T., \& Jacobs, L., “Test-retest reliability and stability of the WAIS: A literature review with implications for clinical practice". Journal of Clinical Neuropsychology, 2, 89-105, January 1980.

[31] Wechsler, D., Escala Weschsler de Inteligencia para adultos. WAIS-III. Manual Moderno, México, 2009, pp. 218.
[32] Sandford, J., Captain's Log Cognitive Trainer, Braintrain, USA. 2011

[33] Tirado, D, Ricardo-Garcell, J., Reyes, Z., Lóyzaga, M., "Caracterización neuropsicológica en subtipos clínicos de un trastorno obsesivo- compulsivo (TOC) en una muestra de pacientes". Salud Mental, vol. 30, No. 1, 1-8, Ene-Feb 2007.

[34] Ardila, A., y Ostrosky, F. Guía para el Diagnóstico Neuropsicológico. Florida International UniversityUniversidad Nacional Autónoma de México, Miami-México., 2012.

[35] Okasha, A., Rafaat, M., Mahallawy, N., Nahas, J, Seif, E., Dawla, A., Sayed, M. \& El Kholi, S., "Cognitive dysfunction in obsessive-compulsive disorder". Acta Psychiatrica Scandinavica, 101, 281-285, April 2000.

[36] Jones, S., Nyberg, L., Sandblom, J., Stigsdotter Neely, A., Ingvar, M., Petersson, K., et al. "Cognitive and neural plasticity in aging: General and task-specific limitations". Neuroscience and Biobehavioral reviews, 30 (6), 864-871, August 2006.

[37] Mercado, E., "Neural and cognitive plasticity: From maps to minds". Psychological Bulletin, 134, 109-137, January 2008.

[38] Willis, S. \& Schaie, K., "Cognitive training and plasticity: Theoretical perspective and methodological consequences". Restorative Neurology and Neuroscience, 27 (5), 375-389, October 2009.

[39] Lövdén, M., Bäckman, L., Lindenberger, U., Schaefer, S. \& Schmiedek, F., "A Theoretical Framework for the Study of Adult Cognitive Plasticity”. Psychological Bulletin, 136 (4), 659-676, July 2010.

[40] Cárdenas, G. y Carreño, V., "La realidad virtual como herramienta para el tratamiento del Trastorno Obsesivo Compulsivo". Revista Digital Universitaria, UNAM. Vol. 13, (3). 3-8, Marzo, 2012. 